\title{
DIAGNOSIS OR AUTO DIAGNOSIS? ENHANCING CONSERVATION PRACTICES OF BUILT CULTURAL HERITAGE. CASE OF STUDY BENIGNO MALO, ECUADOR
}

\author{
G. García Vélez ${ }^{1 *}$, J. Amaya ${ }^{1}$, A. Tenze ${ }^{1}$, F. Cardoso ${ }^{1}$ \\ ${ }^{1}$ City Preservation Management project, Faculty of Architecture and Urbanism of University of Cuenca, Cuenca-Ecuador - \\ kpuligv@hotmail.com*; jaar90@gmail.com; aliciatenze@yahoo.es; faustocardosomartinez@gmail.com
}

\section{Commission II, WG II/8}

KEY WORDS: Participatory action research, heritage values, values-based approach, transdisciplinarity, sustainability

\begin{abstract}
:
The acknowledgment that cultural heritage products are repositories of remarkable cultural values has brought the need for guaranteeing their intergenerational transmission. It has given the reason for the existence of conservation as a discipline. In the last two decades, important shifts have taken place regarding conservation practices. Those practices have moved from an object-centered approach, towards a values-based approach. It implies conservation does not focus solely on guaranteeing the physical permanence of a cultural product but ensuring the maximum transfer of its heritage values. Progressively, conservation is being understood more as a collective dialogue process than a technical issue. This recognition highlights the crucial role that a proper diagnosis might play to guide on this complex process. In this regard, the present work aims to reveal from the socio-economic perspective, the aspects that might influence on the conservation process based on the case of study of the Benigno Malo High school, a heritage asset located in Cuenca World Heritage City, Ecuador. In doing so, it explores the socio-economic dynamics around the cultural heritage asset itself, the territory to which it belongs, and the actors that might influence on its conservation process. But even more, it concludes reflecting around the complementarities and divergences between the notions of diagnosis and autodiagnosis and their contribution for improving current conservation practices.
\end{abstract}

\section{INTRODUCTION}

\subsection{Values-based approach}

The notion of cultural heritage values is determinant for conservation practices. Historically, through what has been called "heritagisation" or "patrimonialization" process, certain cultural values have been exalted over others, transforming them in heritage values. A corollary to this, cultural assets - considered repositories of cultural values- have been transformed into cultural heritage assets. The heritagisation process aims to guarantee the protection and transmission to future generations of those selected values and assets. Initially heritagisation process was fostered worldwide focusing on tangible cultural assets and more recently intangible cultural assets have been included. But, one key aspect to emphasize is that behind those improvements there has been a progressive enrichment in the understanding of cultural heritage values, initially linked to archaeological, historical and aesthetic values so-called conventional values, to recently include, social, economic and environmental values, known as contemporary values.

In the vast literature regarding cultural heritage values of tangible assets, it is very common to find the use of the "palimpsest" analogy to refer to the dynamic nature of heritage values, which are embodied in the same object. In this non-predictable and never closed process of transformation -evident or not-, new cultural values might be revealed and afterwards be considered heritage values, which in addition to previous ones, would reinforce the relevance of protection. But also, on the other hand, precedent heritage values may be lost or diminished during the transformation process, compromising their future transmission.

In this regard, one should bear in mind that the palimpsest analogy is not limited to the physical dimension of the page, which represents any cultural product (tangible or intangible), instead it should be understood in the essence of transformation which means its resignification, as expressed by Caraballo (2008) or the hybridization as conceptualized by García Canclini (1995). Indeed, even though physical transformations are not always evident, new cultural values and consequently cultural heritage values emerge in a very adaptive process overtime.

The result is a conservation notion that has transcended from being synonym of restoration, where practices are limited to physical interventions. Rather than pretending to 'freeze' any cultural heritage product, conservation theories and practices currently aim to negotiate change in a way that it favors the transmission of current cultural heritage values and also its enhancement. This is the notion of "efficient conservation" proposed by Dereck Worthing and Stephen Bond (2008). This premise calls professionals involved to the built heritage sector in the XXI century, to face an important change of mind from 'static' practices of conservation, towards a dynamic understanding which acknowledges that built heritage is part of a major a complex system which changes permanently and it is product of successive interventions over time.

\subsection{The integrated and holistic approach}

In the way to achieve this efficient conservation, authors such as Garcia \& Cardoso (2018) recommend being as exhaustive as possible in the phase of diagnosis. It compels us to adopt a holistic and integrated perspective, for the analysis of the interaction among the heritage assets and its territory. The integrated approach was proposed by the European Charter of the Architectural Heritage at mid of the seventies. At that time the world experimented dramatic physical transformations due to modernization paradigm. In that context, it boosted the protection of modest or contemporary examples of cultural heritage architecture beyond selected elements, which resulted in a harmonious 'whole'. That integrated notion was progressively

\footnotetext{
${ }^{1}$ The palimpsest is the manuscript page that can be erased and reused several times although traces remain as marks inherited from the past.

* corresponding author
} 
echoed by international recommendations, and have expanded its contents to include social and economic dimensions of the territory on which the built cultural heritage is ingrained, until the most recent UNESCO recommendation of Historical Urban Landscape (2011). The holistic approach seeks to contribute to the sustainability of built heritage conservation practices considering that these structures do not only constitute means to understand past, but means to plan our future. Based on the premise that cultural heritage needs to be ingrained in development strategies, which in turn reinforces its own conservation, the holistic approach advocates to joint-work of communities and professionals of the heritage sector.

According to this holistic and integrated approach, at least three aspects should be considered for an accurate diagnosis: Firstly, a spatial analysis based on a multi-scale perspective which goes from the macro (historic area), the meso (community or neighbourhood) and the micro (heritage asset). Secondly, the multi-dimensional understanding of the nature of the places on which economic, social, environmental and cultural dimensions interact in constant flow and, finally, strengthening a network of strategic actors on which the academic, institutional and civil ones might be articulated. All these components require to be observed in a temporal perspective strongly supported on which one already know about the past, to plan the future.

\subsubsection{Social participation}

For a long time, experts have claimed through international congresses and charters that heritage conservation must concern a variety of actors, not only professional groups and authorities. In the last decades, social and community participation has increasingly been accepted in the discourse, however, its practical implementation is often ambitious and not easy to apply. In 1997, the Culture and Development World Commission represented by Pérez de Cuellar, stated that most of the failures of investment projects are due to an 'underestimation' of the importance of the human factor, its complex relationships, values and motivations. The notable lack of involvement of residents and the isolated approach of institutions still seem to be a critical factor in the implication of heritage conservation policies (Garcia, et.al 2015). In fact, anthropologic causes are considered the major threat for cultural heritage conservation worldwide.

Furthermore, community has been recognized as a key factor to guarantee a sustainable process, as long as their knowledge joins that of the network of actors involved (Villasante, 2006; Alberich et al, 2015). Conservation activities are difficult to implement unless a climate of cooperation has been created. Consequently, this could contribute to reduce the 'perceived distance' between themselves and their surrounding heritage site. Secondly, community perceive some benefits from heritage conservation. As part of social benefits, heritage conservation, as a bottom-up process, contributes not only to enhance understanding of the social dynamics, history, and values associated with the site and its people, but also to create synergies among actor networks that impact positively in their well-being. Besides, in economic terms, heritage protection can offer several opportunities for local communities to develop productive strategies. Finally, heritage conservation contributes, even to alleviate environmental concerns, through the adaptive reuse of historic buildings (CHCfE, 2015).

In terms of Villasante (2006), participation implies involving people in all phases of decision making process, against merely informing them of decisions that have been made. According to his studies, participation compromises a listening stage, supported by techniques easy to apply by professionals nonrelated to the social sciences such as drawings, transects and derives walks, timelines, etc., contributing to go beyond the descriptive and static understanding of the territory towards an enriched and dynamic vision. In this regard, special attention will be devoted on identifying the proper techniques and tools to collect information from a variety of actors, which might also be a challenge. Once data is collected, special care must be put on producing integrated documents instead fragmented ones. In fact, Worthing and Bond (2008) asseverate "the more discipline and people involved, the more difficult is to evolve a coherent product". However, integrated diagnostic is not enough to guarantee participation. Returning the information to all actors involved, these are academic, institutional but also 'vivencial experts', become crucial for many objectives. One is to validate possible inferences and assumptions made but the interdisciplinary team, and also to move from complaints to the generation of possibilities for change and co-responsibility, that is, to construct a collective interpretation of information, becoming an integral or comprehensive diagnostic (Alberich et al, 2015).

As part of the devolution, workshops are preferred. Returning the information implicates a key difference between consultative techniques and participatory techniques. Indeed, through this spiral process of listening, analysing and returning information, participatory techniques boost a double fold learning process, sustained in a process of discussion and reflection, sharing individual knowledge and building knowledge in a transparent manner.

\section{CASE OF STUDY: BENIGNO MALO}

\subsection{Brief description of the heritage asset and its territorial context}

The Benigno Malo High school (BMH) is considered one of the most remarkable examples of heritage architecture in Cuenca, Ecuador. It was erected around 1938, in the borders of the World Heritage area named Santa Ana de los Ríos de Cuenca in Ecuador listed by UNESCO (1999). At that time, the historic city experienced a dramatic process of expansion mainly fostered by the massive mobilization of the elites from the core of the city towards the borders of the city, adopting the urban paradigm of that era: the "garden city". In this context, the BMH constitutes a benchmark of that process, reflected on its monumental scale which favours its visual connection from different points of observation to the area; its aesthetic dimension highly influenced by European styles introduced during the Republic period (18201940); and its innovative constructive system on which local skills experimented with arch systems for brick structure (figure $1,2,3)$. From the socio economic perspective, the profile of initial users of this building (students and professors), were related to elites of the local society, which conferred special prestigious to the educative institution. In spite of that importance, this heritage building currently faces an accelerated physical decay and threated by a very dynamic socio-economic environment on which residential functions are progressively substituted by commercial activities. At the end, economic pressures guide physical transformation, putting in risk the principles of the garden city and the future of emblematic buildings such as the BMH. 


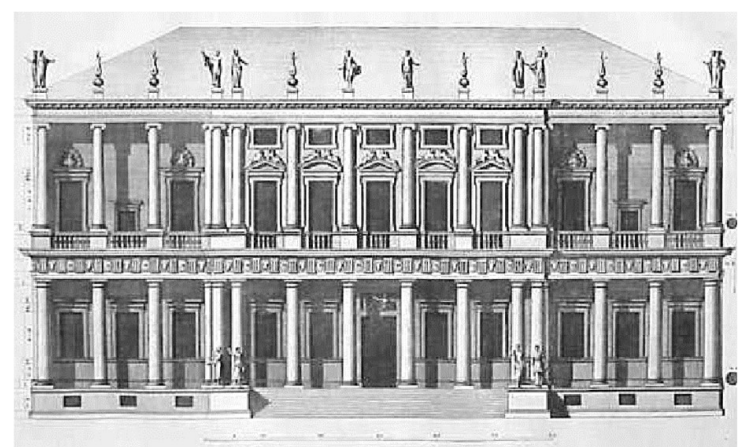

Figure 1. Palazzo Chiericati of Palladio, in Vicenza, Italy. Source: http://www.unav.es/ha/005PALA/005-bertotti/pall-bert012.jpg

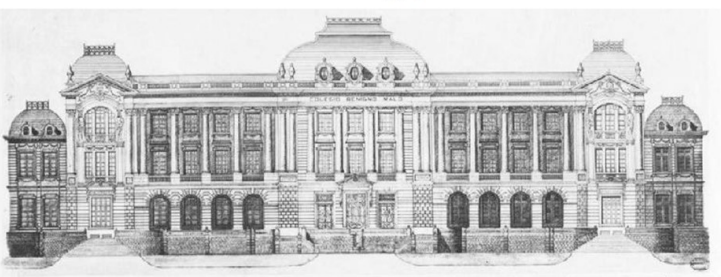

Figure 2. Design for the frontal facade of the BMH. Source: National Photography Fund Archive

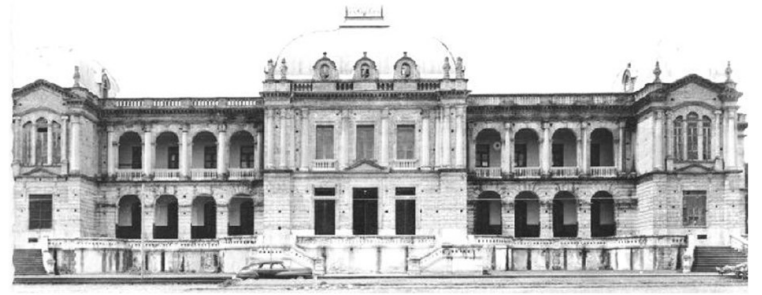

Figure 3. Executed Project. Changes considerably the architectural language in the second floor. Source: National Photography Fund Archive

On 2018, in order to guarantee a good quality in the educative infrastructure and the satisfaction of needs of current occupiers, the Ministry of Education of Ecuador, through its sectional district of Azuay, asked the University of Cuenca, to develop the Restoration studies for the BMH. For the academic actor, it became a great opportunity to develop a proposal nourished by data of secondary sources, but especially for innovating technical diagnosis, designing a participatory process to reach what has been called a participatory diagnosis or a "collective autodiagnosis". This, would imply the knowledge construction based on the exchange of diverse types of knowledge, on this occasion scientific and empirical.

\section{METHODOLOGY}

Methodologically, primary and secondary data were collected and analysed for the diagnosis of the socio-economic component. In a first stage, quantitative, qualitative and spatial methods were combined, such as on-line surveys, interviews, and multilayering. By adopting the integrated and holistic approach, social, economic, environmental and cultural dynamics were explored at two different territorial scales 1) micro scale, referred to the heritage building, considered as the internal dynamics, and 2) intermediate scale referred to the immediate territory on which the building is placed, considered as external dynamics. In a second stage, participatory techniques were adopted to cause that all those people related to the BMH meet and reflect together, and thus, move towards what has been called auto-diagnosis. So that, regarding the actors' network involved in the entire process, were identified the student groups and representatives, alumni, parents, teachers, administrative personal and institutions' representatives such as Culture Ministry, Municipality, National Institute of Cultural Heritage, neighbours and citizens interested in the process.

During the first phase of gathering information to build the socioeconomic diagnostic, secondary data was retrieved mainly from the Municipality of Cuenca and the National Institute of Statistics and Census (INEC, 2010). It consisted on data-bases, which provided information about the economic activities, social profile of inhabitants, environmental aspects such as green areas, public spaces, materiality and typology of buildings placed in the surrounding area (intermediate scale); while registers and files provided by the BMH administration allowed to draft a first approximation to the socio-economic profile of students, educative aspects, infrastructure and institutional management (micro scale). The preliminary findings, based on secondary sources, were contrasted with primary sources. At intermediate scale, surveys were applied to identify the current uses of land on the surrounding area, while at micro scale, on-line surveys were applied to update internal information. Regarding this last, $31 \%$ of the total of professors (150) responded the questioner, while for the students a probabilistic stratified sample was determined observing correspondence with the total population by gender, in the different educative levels (table 1):

\begin{tabular}{|c|c|c|c|c|c|c|}
\hline & \multicolumn{3}{|c|}{ Total } & \multicolumn{3}{|c|}{ Sample } \\
Level & $\mathrm{M}$ & $\mathrm{F}$ & $\mathrm{T}$ & $\mathrm{M}$ & $\mathrm{F}$ & $\mathrm{T}$ \\
\hline First & 199 & 155 & 354 & 77 & 74 & 151 \\
\hline Second & 231 & 136 & 367 & 89 & 65 & 154 \\
\hline Third & 180 & 128 & 308 & 66 & 61 & 127 \\
\hline TOTAL & 610 & 419 & 1029 & 220 & 201 & 421 \\
\hline
\end{tabular}

Table 1. Sample of respondents of the on-line survey

On the second phase, as was aforementioned, participatory methodologies were adopted to reflect collectively and more deeply about the internal and external socio-economic dynamics identified through the quantitative and qualitative analysis. In fact, participatory process compromise at least two main criteria 1) active listening and 2) devolution. Regarding the active listening, in addition of the quantitative and qualitative analysis of data, 105 people -as sample of the diversity of actorsparticipated in a public workshop developed in the BMH heritage building in march 2019. On that occasion, the "world Coffee method' recommended by authors such as Takahashi, Nemoto, Hayashi, \& Horita (2014) was used to favour collective dialogue. The assumed effectiveness of the method for collecting data from large groups of people was taken in advantage to identify the strengths, potentialities, threats and weakness, through open questions such as Which element would/ would not you rescue from the $B M H$ ? Similarly, as a way to express the current tendential and desired scenario for the BMH open questions such as How do you see the BMH today? How BMH could be with / without our intervention? etc., were presented to participants. According to H. Kahn, 1967, in Vergara et. al. (2010), scenarios can be considered as hypothetic sequences of events, built with the purpose to centre attention in the causal aspects into decisionmaking process. In his terms "scenarios are not used to predict the future, rather they are a mechanism that serves to better understand the future" (Vergara et.al 2010:23).

The collected and analysed data derived from the active listening was presented in a second workshop, to a small group (17 
people), but representative of the diversity of actors, as a kind of "devolution". Precisely, returning the information in this workshop, as a face-to-face dialogue space, allowed not only to ponder and refine collected data, like a feedback, but also to contrast and interpret it together, what became in a participatory diagnosis or a collective auto diagnosis. The SWOT analysis merged the identified current internal dynamics of the BMH with the main external dynamics of the immediate context. It observed simultaneously positive and negative aspects distinguishing if those were under or out our control (Ganuza et al, 2010).

That is to say, the auto-diagnosis has to do with the change of focus, in a traditional way of doing in which the diagnosis is made only by the technicians, when after a listening stage they collect the data to interpret them. In this sense the subject interprets, but it is only a technical argument. While in the participatory diagnosis when the technicians collect the information they do not interpret it, but rather organize it, in such a way that all those involved in the matter can make a collective interpretation of the information. In this sense, the group becomes a "collective subject" that also values or constructs, at a given moment, a common truth that serves all of the group. This is what it is call participatory diagnosis or auto-diagnosis, because it is the group itself that interprets the information and synthesizes it in such a way that it serves to continue the process, to take the step towards finding solutions (Villasante, 2006; Alberich et al, 2015).

\section{RESULTS}

\subsection{Technical Diagnosis and collective Autodiagnosis}

As part of the main positive external dynamics identified through the technical diagnosis of the socioeconomic situation of the $\mathrm{BMH}$, regarding environmental aspects it was revealed the strategic location of the $\mathrm{BMH}$, which currently benefits from an important vial network system that connects this area with the rest of the city, and its rural areas. It has favoured the high presence $(25 \%)$ of students who currently come from rural areas. The multi-layering spatial analysis, shown an important concentration of open public spaces, cultural and educative centers and administrative institutions placed in the proximity of the heritage building (radius minor than $500 \mathrm{mts}$ ). Those aspects and the close relation to the Historic City Centre of Cuenca, maximized the potential of the location of the BMH as a privileged and attractive area. Regarding to the socio-economic aspects, the population which currently occupies the surrounding area belongs to younger groups. It might be considered as medium-high economic class who in the majority of case own residential buildings, built with modern materials and well preserved.

On the other hand, as part of the negative external aspects that affect the functions of the $\mathrm{BMH}$, can be mentioned a kind of gentrification process. In fact, the observation of use of land in that area during the last decade (Calderón, 2016) has evidenced a progressive growth of economic activities, while residential functions have decreased significantly. This quantitative analysis becomes even more critical when one observes that the traditional type of architecture designed for dwellings is replaced by new contemporary residential projects that prefer high density and temporary residents. Regarding to the socio-economic aspects, it can be mentioned the few number of potential students that live at major proximity to the $\mathrm{BMH}$ (radius minor than $500 \mathrm{mts}$ ). Finally, an unsafe environment was identified in the immediate context of the $\mathrm{BMH}$, arguing muggings, sale and consume of drugs and alcoholism.
Similarly, the technical diagnosis identified negative and positive aspects regarding the internal dynamics of $\mathrm{BMH}$. In contrast to the initial socio-economic profile of students at the $\mathrm{BMH}$, the current profile of students can be described as medium-low, affected by social difficulties. The results of the sample of students indicates that $2.5 \%$ of the students are economic responsible of their families; $27 \%$ of the students are affected by the migratory phenomena of one member of their nuclear family structure; $2 \%$ of them presents a kind of disability related to visual and audition. Besides $10 \%$ of respondents presents a member of their nuclear family structure with disability, $18 \%$ of these group corresponds to one of the parents. $59 \%$ of the sample has an average of 4,5 people per family.

On the other hand, regarding the physical infrastructure, participants of the on line surveys selected four spaces considered the most important and their current conditions were assessed, resulting in: 1) $42 \%$ of responses referred to sport areas, such as the coliseum, gym, recreational areas, swimming pool, qualified in regular conditions; 2) $20 \%$ referred to basic services such as toilets, medical department, dining room, qualified in bad conditions; 3) $20 \%$ referred to the educative areas such as classrooms, atelier, etc., qualified in regular conditions; 4) $5 \%$ referred to the cultural areas such as the museum, auditorium, library, qualified in good conditions. From the positive side, the technical diagnosis identified areas of interest in the current group of students mainly related to culture and sports. In fact, $41 \%$ of students are interested in Music, $19 \%$ in paint, $18 \%$ and dance. While, regarding sports, the main areas of interest identified were $35 \%$ soccer, $20 \%$ swimming, $17 \%$ Volleyball and $14 \%$ basketball.

As was indicated in the methodology section, preliminary findings obtained through the technical diagnostic about external and internal dynamics, based on qualitative, quantitative and spatial analysis, were contrasted with an active listening process on which actors (105 people) participated in a face-to-face meeting. As result of that, the remarkable historical and cultural value of the BMH was corroborated. In the view of participants, it represents a kind of "master piece" in the comprehension of the history of the whole city of Cuenca. But, additionally to the aesthetic dimension, it was relevant to notice the emphasis on its function and, in this sense, it was reiterative the statement "keep it as a respectable high school, rather than a new museum". In this regards, participants claimed on the importance of extracurricular activities, such as sports, which currently are underestimated. It has affected directly the current state of conservation of areas such as the green fields, swimming pool and the gym. In similar manner than the quantitative analysis, minority voices, but no least important, claimed for accessibility and physical improvements to respond to the needs of people with different kind of disabilities. Finally, participants confirmed the perception of insecurity, clarifying that it did not affect solely the external environment, but also the internal one.

These results were returned to a group of diverse actors (17 people), adopting one more time a face-to-face dialogue. On that occasion the causes of the identified problems were deepened analyzed. Regarding to this, participants mainly referred to the lack of interest of students, professors and students' parents, it means the internal inhabitants of the building. This group mainly referred to the presence of dirty and dark spaces as the place to favor drug sale, unsafety places and insalubrity. At the end, this meeting served also to identify an important inconsistence of data collection surveys, which should continue in exploration. According to this surveys, decision-making process in the 
institution involves only school directors, while during the meeting, participants agree that decisions responds to a dialogue which include a variety of groups such as alumni and students. At the same time as this article is being elaborated, other activities are being designed with the aim of provoking encounters between actors so that, through dialogue and reflection between them, reconsiderations can be made both to the diagnosis and to the ways of solution that are reflected in the physical draft.

\section{CONCLUSIONS}

The holistic and integrated approach proposed in this work to improve conventional restoration practices of heritage buildings, bets for participation as a key factor to move the technical diagnosis, to auto diagnosis. It implies to involve community in a dialogue between professional experts and empirical experts, substituting the very common consultative way to build knowledge. In this sense, moving from the diagnosis towards auto diagnosis means sustain a transparent process of negotiation of change among actors. Besides, even though technical diagnosis might attempt to be as exhaustive as possible, it does not favor a process of engagement between the various actors involved in future phases such as planning and management which are part of conservation process. This is precisely, the added value of auto diagnosis, on which various stakeholders, social actors, and local authorities, communicate, and reach a common comprehension and compromise themselves to decide how might be their heritage preserved.

This article shown the results of a collective process on which were identified the territorial factors (external and internal) that might affect the restoration project of the BMH.

Regarding the external aspects, it revealed important the diversity of economic activities, which might reinforce the educational activities of the BMH such as cultural centers, recreational areas, public spaces and other primary and professional institutions. Inversely, the improvement in the current infrastructure of the BMH could expand its offer to attend an external demand, maximizing the use of its spaces by external actors. In this sense, the restoration project might enhance the two-fold interaction between the $\mathrm{BMH}$ and its immediate context. Moreover, favoring the meet of internal users with external users on these spaces might favor to reduce the struggles perceived between inhabitants of the area (medium-high incomes) with users of the BMH (medium-low incomes). In fact, quantitatively, those users represent $25 \%$ of the total inhabitants in the area and the majority of the problems are attributed to their presence.

While, regarding the internal aspects, socio-economic diagnosis and self-diagnosis revealed the minimization of familiar aspects experienced by the BMH students. However, precisely, those aspects might have a direct relation with low academic performance, or insecurity environment perceived inside and outside BMH.

But at the same time, the studies developed shown a great interest of students on extracurricular activities related to ateliers, music and dance. The restoration project might maximize that interest designing areas to cultivate and to maximize it as a kind of cultural therapy to deal with this difficult task, while deepest studies have to be developed to prevent more than to react to this negative effects. These more in-depth studies could take place in a process that favors encounters, more or less what is proposed in the doc of institutional management: "it would be important to consider the realization of a process, inside and outside the center for mutual knowledge and to discover what areas and what resources they could share. This implies creating open and inclusive listening mechanisms, starting in the different spheres that make up the campus to improve, among others, coexistence and security in the center. It is necessary to involve, above all the student body, in the analysis, reflection on reality and make proposals for improvement, so that this collective gains autonomy from respect and inclusion, which would gradually result in an internalization of the values pillars of Benigno, not only from theory, but above all from practice.

In sum, the restoration of the BMH might be the opportunity to favor not only the physical preservation and enhancement of its infrastructure, but also to became in a place for meeting and dialogue. In line with this, the intervention process should generate, on the one hand, a positive impact in the formal learning processes, and on the other hand, to create ways to reconcile tensions due to the identified social differences between insiders and outsiders. Finally, considering inseparably those aspects (physical and social) will serve to mitigate problems detected, and probably in long term enhance the individual realities of the students.

\section{ACKNOWLEDGEMENTS}

This research was developed as part of the Restoration project of the Benigno Malo High school promoted by the Ministry of Education of Ecuador. The authors express their gratitude to the technical team and administrative team of the BMH for their support during the process of gathering and analysing of information.

\section{REFERENCES}

Calderón, R., Chica, J., Roche, K., 2016. Plan de Conservación de El Ejido de la ciudad de Cuenca. Universidad de Cuenca, Ecuador.

Caraballo. C., 2008. El patrimonio cultural y los nuevos criterios de intervención. La Participación de los actores sociales. Revista Palapa Vol. 3, Núm. 1. ISSN: 1870-7483

CHCfE., 2015. Cultural Heritage Counts for Europe Consortium. Retrieved from: http://blogs.encatc.org/culturalheritagecountsforeurope/outcome s/

Ganuza, E., Olivari, L., Paño, P., Buitrago, L., Lorenzana, C., 2010. La democracia en acción: una visión desde las metodologías participativas. Editorial Antígona, España

García, G., Cardoso, F., Van Balen, K., (2015) “The Challenges of Preventive Conservation theory applied to Susudel, Ecuador." in Reflections on Cultural Heritage Theories and Practices. A series by the Raymond Lemaire International Centre for Conservation. Leuven-Belgium, 117-130p.

García, G., Cardoso F., 2018. "Patrimonio Cultural y Desarrollo. Las campañas de Mantenimiento". Seminario Internacional: Patrimonio Cultural, Avances y Desafíos. Ministerio de Cultura. Quito, Ecuador. 44-57p

García-Canclini, N., 1995. Consumidores y Ciudadanos. 
The International Annals of the Photogrammetry, Remote Sensing and Spatial Information Sciences, Volume IV-2/W6, 2019 27th CIPA International Symposium "Documenting the past for a better future", 1-5 September 2019, Ávila, Spain

Editorial Grijalbo, 1era. Edición, México, D.F.

INEC., 2010. Instituto Nacional de Estadísticas y Censos del Ecuador. Censo de Población y Vivienda. Retrieved from: http://www.ecuadorencifras.gob.ec/censo-de-poblacion-yvivienda/

Alberich, T., Fernández, A., Martínez, M., 2015. Metodologías participativas: Sociopraxis para la creatividad social.

RedCIMAS. Editorial Dextra. Madrid.

Takahashi, M., Nemoto, K., Hayashi, N., \& Horita R., 2014. The measurement of dialogue: From a Case Study of the Workshop Using World Café as a Collective Dialogue Method. Journal of Information Processing 22(1): 88-95

UNESCO., 2011. Recommendation on the Historic Urban Landscape. Retrieved from: http://portal.unesco.org/en/ev.phpURL_ID $=48857 \& U R L \_D O=D O \_T O P I C \& U R L \_S E C T I O N=20$ 1.html

Vergara, J., Fontalvo J., Maza, F., 2010. La planeación por escenarios: Revisión de conceptos y propuestas metodológicas PROSPECTIVA, vol. 8, núm. 2, julio-diciembre, 2010, pp. 2129 Universidad Autónoma del Caribe.

Villasante, T., 2006. Desbordes creativos: estilos y estrategias para la transformación social. Editorial Catarata. Madrid, España.

Worthing, D., and Bond, S., 2008. Managing Built Heritage. The rol of culture significance. Blackwell Publishing editorial. ISBN 978-1-4051-1978-8, Oxford, UK. 